\title{
Review Paper: Barriers and Challenges of Implementing Telerehabilitation: A Systematic Review
}

\author{
Niloufar Rabanifar ${ }^{1}$ (D), Kianoush Abdi $^{1^{*}}$ (iD)
}

1. Department of Rehabilitation Management, University of Social Welfare and Rehabilitation Sciences, Tehran, Iran

\begin{tabular}{c|l}
$\begin{array}{c}\text { Use your device to scan } \\
\text { and read the article online }\end{array}$ & $\begin{array}{l}\text { Cftation: Rabanifar N, Abdi K. Barriers and Challenges of Implementing Telerehabilitation: A Systematic Review. Iranian } \\
\text { Rehabilitation Journal. 2021; 19(2):121-128. http://dx.doi.org/10.32598/irj.19.2.1404.1 }\end{array}$ \\
dol'http://dx.doi.org/10.32598/irj.19.2.1404.1
\end{tabular}

\section{(c) (1) (3)}

Article info:

Received: 14 Apri 2021

Accepted: 17 May 2021

Available Online: 01 June 2021

Keywords:

Barriers, Challenges,

Obstacles, Telerehabilitation,

Telemedicine

\section{ABSTRACT}

Objectives: Telerehabilitation (TR) is an alternative approach for providing rehabilitation services in some situations, like Coronavirus Disease 2019 (COVID-19) pandemic. There exist some obstacles, especially during the pre-implementation phase of TR, necessitating an investigation of existing local evidence. This research aimed to investigate the challenges of TR.

Methods: Five electronic databases (Scopus, PubMed, Google Scholar, SID, \& Magiran) were searched for studies published in English and Persian language from 2011 to February 2021. Search results in all databases provided a total of 598 articles. After reviewing the titles of the articles, we excluded 574 articles as they were duplicated and/or irrelevant. Finally, based on the inclusion and exclusion criteria, 11 articles have remained.

Results: Most extracted articles were published in $2020(n=4)$. The remaining articles disturbed between 2013 until 2021. These articles were mostly reviews, case reports/series, or qualitative studies and surveys. Geographically, $27 \%$ of the final selected papers belonged to the USA, $46 \%$ to Asia, and $27 \%$ to Europe. Outcomes in studies mostly included TR advantages and disadvantages, facilitators, challenges, and barriers.

Discussion: Studies specified numerous challenges for TR implementation. The main challenges in the technologies used in TR were the awareness and culture of individuals and the TR infrastructure. Despite these barriers, TR could be a better treatment selection in some patients. Therefore, it is necessary for health policymakers, and especially rehabilitation managers, technology developers, scientists, and clinicians to cooperatively make serious efforts to remove these barriers. 


\section{Highlights}

- The internet is the overall number one barrier to telehealth.

- Resistant of the acceptance of TR among patients and clinicians and the lack of knowledge and skills required in TR are major challenges respecting human factors.

- The attitudes of policymakers prevent the use of TR services.

\section{Plain Language Summary}

We reviewed studies that have identified barriers and challenges to TR. It is important to investigate this issue. This is because many people with disabilities who need rehabilitation services are unable to walk distances to the clinic. Especially during the COVID-19 pandemic, the need for TR has increased. Therefore, it is very important to study the obstacles to its implementation to help people with disabilities by eliminating them and determining relevant policies and laws. In this study, many obstacles have been identified; the most important of which were the problems of accepting stakeholders, the internet, infrastructure, and the technology used.

\section{Introduction}

he Coronavirus Disease 2019 (COV-

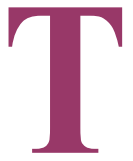
ID-19) pandemic not only affected the financial and social life aspects of individuals but also changes the conventional method of managing patients [1] To prevent COVID-19 spread, some preventive measures should be taken, such as wearing masks and gloves, adopting careful personal hygiene, as well as applying the so-called 'social distancing' [2]. Telerehabilitation (TR) is a reliable approach to provide rehabilitation programs, remotely. In the past few years, it has been supported that significant clinical improvements can be achieved by applying TR; thus, that they are equal to the conventional clinical rehabilitation treatment. Implementing TR has especially become more crucial in the COVID-19 pandemic; the clinical face-toface treatment is at odds with preventive measures and it is dangerous. Currently, remote communication between healthcare professionals and patients is significantly facilitated due to progress in communication and information technologies [3]. This method can provide various rehabilitation services, such as monitoring, assessment, intervention, prevention, supervision, education, consultation, and counseling [4]. Furthermore, applying $\mathrm{TR}$ is becoming more viable as the speed and quality of communication technologies enhance [3]. However, the efficiency of this model of delivery remains unclear, compared with face-to-face delivered rehabilitation [5].

TR has numerous advantages. It can enhance the standard of services by monitoring patients at their place of residence, particularly for individuals who live far from urban centers [6]. TR can also adapt long-lasting rehabilitation programs with a social and productive life. The term TR stands for any home-based interventions, regardless of which technology is used [7]. Its programs can overcome numerous practical barriers to rehabilitation participation and support long-term adherence to a healthy lifestyle [8]. TR is mainly applied for patients with spinal cord and brain injury, stroke, or joint replacement; it usually involves audio and video technologies [4]. There exist multiple rehabilitation therapy methods and programs based on TR. Besides, they commonly require the clinical professionals to check the patient's condition; they present rehabilitation therapy examples to the patient or their guardian and use photos or videos to instruct how rehabilitation therapy should be performed [9]. However, no evidence demonstrated the TR capability to improve participation rates. Another valuable benefit of TR is providing efficient feedback that allows patients to follow their improvement process. This could improve patients' self-management skills; subsequently, it supports more sustainable behavioral change [8]. Some benefits of TR include the following: greater privacy; presented at one's pace; minimal travel/ transportation barriers; higher patient independence; combination with telemonitoring; protection from virus infections; providing core components at home; possible tailoring, and cost-effectiveness [1,8].

Over the recent decade, various TR methods have been employed. However, our healthcare systems have implemented TR in clinical practice disappointingly low. Furthermore, most TR trials have only focused on the physi- 
cal activity component and exercise training; however, TR ideally involves addressing all core components of rehabilitation tailored to the risk profile of the individual patient [8]. TR has some challenges concerning implementation. The present study reviewed the articles that addressed these challenges and barriers.

\section{Methods}

We performed a global systematic review through various national and international electronic databases to identify studies that addressed the barriers and challenges of implementing TR. In this article, we used items for reporting a literature review to present the obtained results.

\section{Study design and data extraction}

We conducted a systematic review to explore the barriers of TR. The related articles published in English and Persian languages from 2011 to February 2021 were searched in popular scientific databases (Scopus, MEDLINE/ PubMed, \& Google Scholar) as well as domestic databases (Magiran \& SID). Google Scholar browser was also used to find relevant resources and complete the search coverage.

The first step of our search consisted of the following keywords: ('barriers' OR 'obstacles' OR 'challenges') AND ('telerehabilitation' OR 'telemedicine'). In this study, we surveyed various published papers. The statistics of searched papers and abstracts are presented in Figure 1. This diagram illustrates the most recent search. This review required no Institutional Review Board (IRB) ap- proval or consent, as it assessed articles without individually identifiable human subject information. Unfortunately, no Persian study was found in the domestic databases.

Two researchers independently decided whether to submit articles, and disputes were resolved in consultation with each other. Additionally, a list of sources of searched articles was used to find the related articles. Accordingly, 598 articles were identified.

\section{Inclusion and exclusion criteria}

In this study, to select the relevant articles, the following criteria were used: published papers; published articles included only if the focus of the article was to explore barriers of TR; if the papers were published in English and Persian, and their free full texts were available. The exclusion criteria included studies outside the field of rehabilitation; articles in languages other than English and Persian, and letter to editor articles.

\section{Results}

Preliminary search results in all databases provided a total of 598 articles. After searching various databases, all identified articles were imported into EndNote, and duplicated titles were removed. Of these, 24 articles were included. Accordingly, we removed duplicates by only examining the titles. Then, the abstracts of the 24 articles met the inclusion criteria of this review. The fulltexts of 24 articles were reviewed; eventually, 11 articles remained for further examination and no new relevant studies were identified.

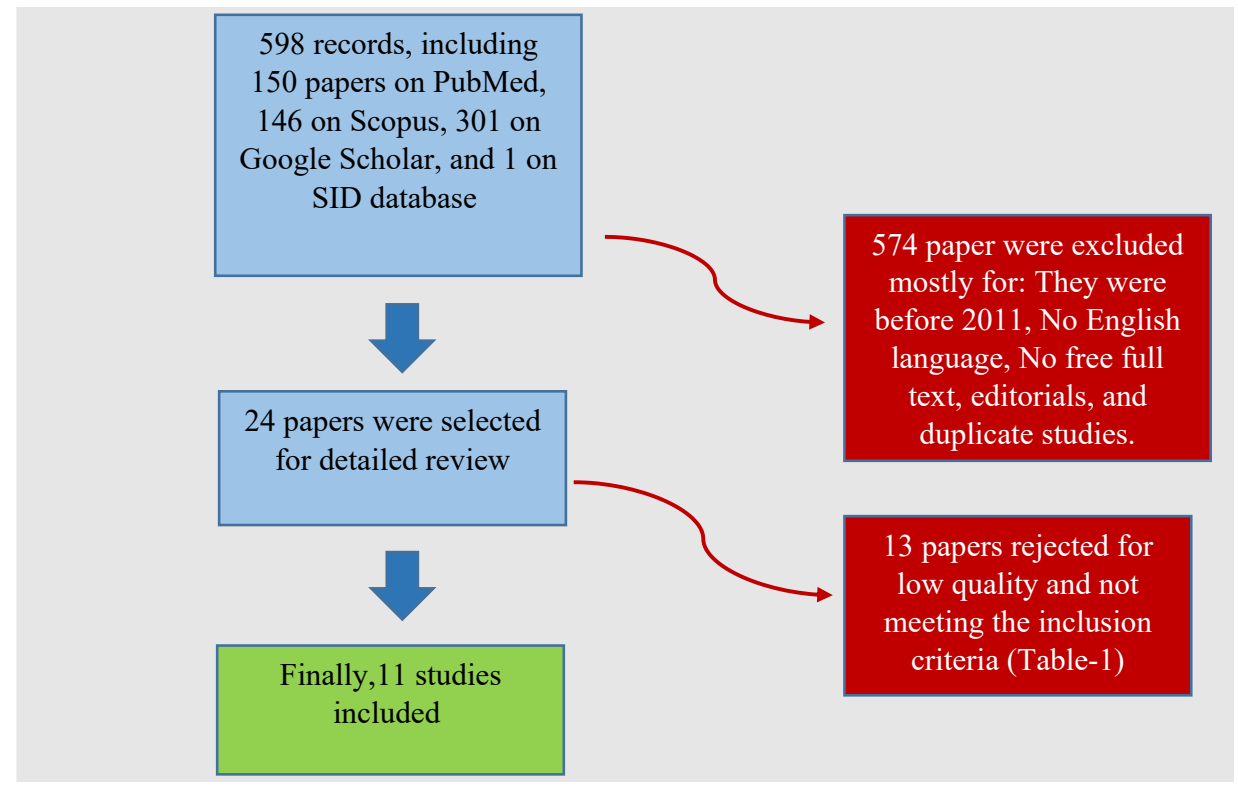

Figure 1. The diagram of survey process and opting articles

Mranian Rehabilitation Journa 

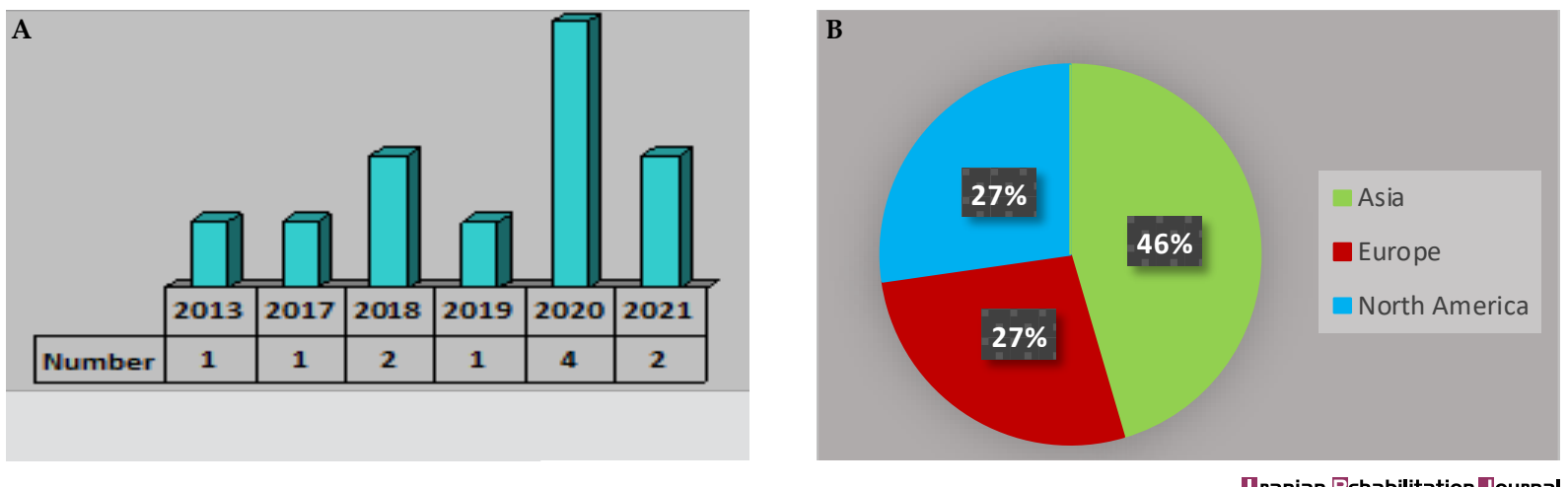

Figure 2. Summary of the included articles based on the year of publication and area (A); the distribution of the selected articles by geographic area (B)

Figure 2 and Table 1 summarize the features of the 11 articles extracted. Most of the extracted articles were published in $2020(\mathrm{n}=4)$. The remaining articles disturbed between 2013 and 2021. The selected articles were mostly review, qualitative, case reports/series, and survey studies. Geographically, $27 \%$ of the final selected papers were performed in the USA, $46 \%$ in Asia, and $27 \%$ in Europe.

\section{Discussion}

Several barriers and obstacles need to be considered in implementing TR. Despite the theoretical advantages of TR over conventional rehabilitation, few studies have evaluated patient satisfaction or acceptance of this rehabilitation method. Furthermore, those studies have found conflicting results for this variable. Further studies are required to evaluate the cost-effectiveness of this rehabilitation model, the barriers encountered by patients when performing TR, and the patients' acceptance of the model [21]. According to studies, numerous factors can help TR to develop at a slower pace and require further time to be able to convince the patient of its effectiveness as conventional approaches. The current study reviewed the challenges and barriers to the implementation of TR and the evaluation of the published articles points as per the following:

Jongbae Kim et al. in 2021 highlighted a lack of standardization of reported neurological levels of injury throughout the study. Besides, they outlined inconsistencies in using generalized terms with increased errors and increased skepticism about service delivery. They also highlighted potential biases that obscured the facts. Other challenges mentioned in providing TR for individuals with spinal cord injury in this study included a tendency to conventional rehabilitation methods due to the ease of informing the therapist of their sexual problems; in providing TR, the lack of technological advancement for it remained an obstacle despite advances in telemedicine [10]

Sometimes, devices and technologies used in TR (tactile feedback technology for motor impairments) have limitations that may lead to poor patient satisfaction and complicate performing TR. These disadvantages include the unpleasant feeling, the different perceptions, and the unpleasant sensation of different patients from the vibration of the device on their body [11]. Providing proper equipment was another challenge to TR implementation. Notably, we cannot optimize TR just by integrating a camera into an existing workstation. For TR, a onesize-fits-all method does not suit all therapy approaches. It involves setting different options depending on the type of therapy. Additionally, TR equipment should be adaptable to various scenarios [12]. Furthermore, some user interface issues, including a screen reader, captions, magnification, color, sign language, and contrast must also be managed. Besides, bio peripherals, including instruments that measure blood glucose level and pressure, and other vital signs should be modified for use in the tele-evaluation of individuals with disabilities The design of new bio peripherals involves improving clinicians' capability to tele-examine individuals with problems, such as manual dexterity or physical mobility disorders that affect the ability to interact with such bio peripherals [14].

Other barriers were technical issues, the lack of information, the lack of involvement in planning, the shortage of exposure to e-healthcare information, resistance to change, the lack of using hardware and software, low connectivity, staff skill problems, and high-cost provider's willingness, and the location of the healthcare institute. In addition to these limitations, the attitudes of policymakers impact the use of TR services $[13,16]$. 
Table 1. Studies relevant to TR

\begin{tabular}{|c|c|c|c|c|}
\hline $\begin{array}{l}\text { First Author, Study } \\
\text { Design (Year) }\end{array}$ & Title & Methods & Outcomes & Country \\
\hline $\begin{array}{l}\text { Jongbae Kim, Sys- } \\
\text { tematic review and } \\
\text { Qualitative synthesis } \\
\text { of randomized Trials1 } \\
\text { (2021) [10] }\end{array}$ & $\begin{array}{l}\text { Substantiating Clinical Effec- } \\
\text { tiveness and Potential Barriers } \\
\text { to the Widespread Implemen- } \\
\text { tation of Spinal Cord Injury } \\
\text { Telerehabilitation: A System- } \\
\text { atic Review and Qualitative } \\
\text { Synthesis of Randomized Tri- } \\
\text { als in the Recent Past Decade }\end{array}$ & $\begin{array}{l}\text { A qualitative synthesis } \\
\text { of randomized studies }\end{array}$ & $\begin{array}{l}\text { Quantitative outcome measure- } \\
\text { ments demonstrated a positive } \\
\text { impact across studies. }\end{array}$ & South Korea \\
\hline $\begin{array}{l}\text { Shirley Handelzalts, } \\
\text { Review (2021) [11] }\end{array}$ & $\begin{array}{l}\text { Integrating Tactile Feedback } \\
\text { Technologies into Home- } \\
\text { Based TR: Opportunities and } \\
\text { Challenges in Light of COV- } \\
\text { ID-19 Pandemic }\end{array}$ & $\begin{array}{l}\text { Reviewing the cur- } \\
\text { rent technologies for } \\
\text { applying mechanical } \\
\text { tactile feedback }\end{array}$ & $\begin{array}{l}\text { The adding of tactile devices to } \\
\text { home-based TR programs can } \\
\text { improve patients' functional } \\
\text { gains and standard of life using } \\
\text { practice in an augmented envi- } \\
\text { ronment with tactile feedback } \\
\text { and tactile interactions. }\end{array}$ & Switzerland \\
\hline $\begin{array}{c}\text { Sergio Romero, } \\
\text { Qualitative research } \\
\text { (2020) [12] }\end{array}$ & $\begin{array}{l}\text { TR for Rural Veterans: A Qualita- } \\
\text { tive Assessment of Barriers and } \\
\text { Facilitators to Implementation }\end{array}$ & $\begin{array}{l}\text { A qualitative study } \\
\text { employing the reach, } \\
\text { effectiveness, adop- } \\
\text { tion, implementation, } \\
\text { and maintenance } \\
\text { framework }\end{array}$ & $\begin{array}{l}\text { Three themes were recognized } \\
\text { uncovering main cultural, infra- } \\
\text { structural, and logistical, and en- } \\
\text { vironmental barriers hindering } \\
\text { the reach, adoption, and imple- } \\
\text { mentation of TR. }\end{array}$ & USA \\
\hline $\begin{array}{l}\text { Faizaan Ka shoo, } \\
\text { Survey (2020) [13] }\end{array}$ & $\begin{array}{l}\text { Knowledge, Attitude, and Bar- } \\
\text { riers to TR-Based Physical Ther- } \\
\text { apy Practice in Saudi Arabia }\end{array}$ & $\begin{array}{l}\text { The study was per- } \\
\text { formed through an } \\
\text { online survey emailed } \\
\text { to the PTs working in } \\
\text { hospitals across the } \\
\text { KSA }\end{array}$ & $\begin{array}{l}\text { The key barriers were techni- } \\
\text { cal problems and costs related } \\
\text { to implementing TR in physical } \\
\text { therapy settings. }\end{array}$ & Saudi Arabia \\
\hline $\begin{array}{l}\text { Thira M. Anna } \\
\text { swamy, Review } \\
\text { (2020) [14] }\end{array}$ & $\begin{array}{l}\text { Telemedicine barriers and chal- } \\
\text { lenges for persons with disabil- } \\
\text { ities: Covid-19 and beyond }\end{array}$ & $\begin{array}{l}\text { Reviewing the papers } \\
\text { that comprised the } \\
\text { challenges of TR }\end{array}$ & $\begin{array}{l}\text { Several barriers and challenges } \\
\text { remained that must be system- } \\
\text { atically evaluated. }\end{array}$ & USA \\
\hline $\begin{array}{l}\text { Carl Froilan D. } \\
\text { Leschaco, Review } \\
\text { (2020) [15] }\end{array}$ & $\begin{array}{l}\text { challenges to the Emergence } \\
\text { of TR in a Developing Country: } \\
\text { A Systematic Review }\end{array}$ & $\begin{array}{l}\text { TR-related publica- } \\
\text { tions searched where } \\
\text { in Filipinos, i.e., } \\
\text { involved as investiga- } \\
\text { tor or population }\end{array}$ & $\begin{array}{l}\text { The lack of data on TR exists in } \\
\text { the Philippines. Local attempts } \\
\text { can concentrate on identifying } \\
\text { or managing the most press- } \\
\text { ing human, organizational, and } \\
\text { technical barriers to the imple- } \\
\text { mentation of TR in the country. }\end{array}$ & Philippines \\
\hline $\begin{array}{l}\text { Mahdi Bahari, Case } \\
\text { study (2019) [16] }\end{array}$ & $\begin{array}{l}\text { Exploring Barriers that Impact TR } \\
\text { Readiness: A Case Study of Reha- } \\
\text { bilitation Centre in Malaysia }\end{array}$ & $\begin{array}{l}\text { A semi-structured } \\
\text { interview, involving } 23 \\
\text { clinical professionals }\end{array}$ & $\begin{array}{l}\text { The study determined } 7 \text { barriers } \\
\text { that affect Tele Rehab readiness. }\end{array}$ & Malaysia \\
\hline $\begin{array}{l}\text { Christina Sadolin } \\
\text { Damhus, Qualitative } \\
\text { research [17] }\end{array}$ & $\begin{array}{l}\text { Barriers and enablers of COPD } \\
\text { TR - a frontline staff perspective }\end{array}$ & $\begin{array}{l}\text { Semi-structured indi- } \\
\text { vidual and focus group } \\
\text { interviews with } 25 \\
\text { health professionals }\end{array}$ & $\begin{array}{l}\text { It recognized } 6 \text { main domains } \\
\text { necessary for understanding the } \\
\text { enablers and barriers of TR from } \\
\text { a staff perspective. }\end{array}$ & Denmark \\
\hline $\begin{array}{l}\text { Manisha Pramod } \\
\text { Shenoy, Review } \\
\text { (2018) [18] }\end{array}$ & $\begin{array}{l}\text { Identifying the Challenges } \\
\text { and Cost-effectiveness of TR: } \\
\text { A Narrative Review }\end{array}$ & A narrative review & $\begin{array}{l}\text { It mostly addressed exploring } \\
\text { challenges faced by its users, } \\
\text { gaps, and goal means for recti- } \\
\text { fying issues and for establishing } \\
\text { cost-effectiveness. }\end{array}$ & India \\
\hline $\begin{array}{l}\text { Davide Calvaresi, } \\
\text { Review (2017) [19] }\end{array}$ & $\begin{array}{l}\text { Agent-based systems for TR: } \\
\text { strengths, limitations and fu- } \\
\text { ture challenges }\end{array}$ & $\begin{array}{c}\text { Reviewing articles } \\
\text { about technology } \\
\text { and robotic in the TR } \\
\text { approach }\end{array}$ & $\begin{array}{l}\text { This study provided a quick over- } \\
\text { view of the state of the art, ex- } \\
\text { ploring video-based, wearable, } \\
\text { robotic, distributed, and game } \\
\text { TR solutions. }\end{array}$ & Italy \\
\hline $\begin{array}{c}\text { Jana Cason DHS, } \\
\text { Commentary present } \\
\text { (2013) [20] }\end{array}$ & $\begin{array}{l}\text { TR: Current Challenges to De- } \\
\text { ployment in the United States }\end{array}$ & $\begin{array}{l}\text { Reviewing articles } \\
\text { about TR }\end{array}$ & $\begin{array}{l}\text { This study presented existing bar- } \\
\text { riers to the implementation of TR } \\
\text { in the United States: profession- } \\
\text { centric nomenclature, limited } \\
\text { efficacy research, inter-state li- } \\
\text { cense transportability challenges, } \\
\text { and insufficient reimbursement. }\end{array}$ & USA \\
\hline
\end{tabular}


Thira M. Anna Swamy et al. reported the challenges and barriers of TR for individuals with a disability, as follows: infrastructure and access; operational conflicts and systems; logistical; regulatory; communication, and unique challenges [14]. The barriers and challenges of TR can also be categorized as follows:

Respecting human factors, the lack of general acceptance of telehealth, the deficits of knowledge and skills, and anxieties related to private data security. Concerning the various mentioned organizational factors in the literature as the main identified barriers of TR implementation, the most frequent characteristics were no appropriate health information systems framework, the lack of national e-health policies or laws, data privacy measures, and governance measures. Among all individual factors across categories, the lack of access to the internet was the main barrier to telehealth [15].

Another factor was that numerous elderly patients that require continuous rehabilitation have inadequate information about how to use smart devices, while these individuals with limited performance, need the help of technological devices. Fast and reliable internet connections and the need for secondary equipment with the knowledge of their performance are tangible barriers to establish stability and ensure perfect interventions for the optimal clinical care of this population. Eventually, protecting personal data against unintended leakage and securing remains a serious challenge in TR $[10,17]$.

In summary, despite studies on the barriers and challenges of TR, few relevant solutions have been extracted. Obstacles in the technologies required for this approach, whether in the hardware sector or the software sector and infrastructures have been found in most studies [11-13, 15, 19, 20]; accordingly, further research on the approaches to overcome these barriers is necessary.

\section{Conclusion}

Studies signified numerous challenges for TR implementation. The main challenges in the technologies used in TR are the awareness and culture of the individuals and the TR infrastructure. Despite these barriers, TR could be a better treatment option for some patients. Furthermore, it has considerable advantages, although further study is required to investigate its effectiveness in other conditions [21, 22]. With the development of technology, and in some conditions that individuals with a disability cannot travel for face-to-face interventions, for example in the COVID-19 pandemic, the need for TR has increased and simultaneously has sped up the adop- tion of digital culture, worldwide. Therefore, it is necessary for the governments, health policymakers, and especially rehabilitation managers, technology developers, scientists, and clinicians, to cooperatively make serious effort to remove these barriers respecting engineering, technology, the internet, and community culture; thus, they could assist individuals with disabilities to improve their quality of life.

\section{Ethical Considerations}

\section{Compliance with ethical guidelines}

There were no ethical considerations to be considered in this research.

\section{Funding}

No funding was provided for this research.

\section{Authors' contributions}

All authors made considerable contributions to all the conception and design of the study, analysis, and interpretation of the result, writing of the manuscript, and revising it. All authors read and approved the final version of the submitted manuscript.

\section{Conflict of interest}

The authors declared no conflicts of interest

\section{References}

[1] Rabanifar N, Abdi K. Letter to Editor: Telerehabilitation: A Useful and appropriate approach for people with disability in Covid-19 pandemic. Medical Journal of the Islamic Republic of Iran. 2021; 35(1):125-6. [DOI:10.47176/mjiri.35.18]

[2] Maggio MG, De Luca R, Manuli A, Calabrò RS. The five ' $W$ ' of cognitive telerehabilitation in the Covid-19 era. Expert Review of Medical Devices. 2020; 17(6):473-5. [DOI:10.1080/174 34440.2020.1776607]

[3] Laver KE, Adey-Wakeling Z, Crotty M, Lannin NA, George S, Sherrington C. Telerehabilitation services for stroke. The Cochrane Database of Systematic Reviews. 2013; 2013(12):CD010255. [DOI:10.1002/14651858.CD010255.pub3] [PMID]

[4] Bittner AK, Yoshinaga PD, Wykstra SL, Li T. Telerehabilitation for people with low vision. The Cochrane Database of Systematic Reviews. 2020; 2(2):CD011019. [DOI:10.1002/14651858.CD011019.pub3] [PMID]

[5] Jansson MM, Rantala A, Miettunen J, Puhto A-P, Pikkarainen $M$. The effects and safety of telerehabilitation in patients with 
lower-limb joint replacement: A systematic review and narrative synthesis. Journal of Telemedicine and Telecare. 2020; 1357633X20917868. [DOI:10.1177/1357633X20917868] [PMID]

[6] Wang Q, Lee RL, Hunter S, Chan SW. The effectiveness of internet-based telerehabilitation among patients after total joint arthroplasty: A systematic review and meta-analysis of randomised controlled trials. Journal of Telemedicine and Telecare. 2021; 1357633X20980291. [DOI:10.1177/1357633X20980291] [PMID]

[7] Di Tella S, Pagliari C, Blasi V, Mendozzi L, Rovaris M, Baglio F. Integrated telerehabilitation approach in multiple sclerosis: A systematic review and meta-analysis. Journal of Telemedicine and Telecare. 2020; 26(7-8):385-99. [DOI:10.1177/1357633X19850381] [PMID]

[8] Scherrenberg M, Wilhelm M, Hansen D, Völler H, Cornelissen V, Frederix I, et al. The future is now: A call for action for cardiac TR in the COVID-19 pandemic from the secondary prevention and rehabilitation section of the European Association of Preventive Cardiology. European Journal of Preventive Cardiology. 2021; 28(5):524-40. [DOI:10.1177/2047487320939671]

[9] Chang MC, Boudier-Revéret M. Usefulness of telerehabilitation for stroke patients during the COVID-19 pandemic. American Journal of Physical Medicine \& Rehabilitation. 2020; 99(7):582. [DOI:10.1097/PHM.0000000000001468] [PMID]

[10] Lee S, Kim J, Kim J, Kim J. Substantiating Clinical effectiveness and potential barriers to the widespread implementation of spinal cord injury TR: A systematic review and qualitative synthesis of randomized trials in the recent past decade. Telemedicine Reports. 2021; 2(1):64-77. [DOI:10.1089/ tmr.2020.0026]

[11] Handelzalts S, Ballardini G, Avraham C, Pagano M, Casadio $\mathrm{M}$, Nisky I. Integrating tactile feedback technologies into home-based TR: Opportunities and challenges in light of COVID-19 pandemic. Frontiers in Neurorobotics. 2021; 15:617636. [DOI:10.3389/fnbot.2021.617636] [PMID]

[12] Hale-Gallardo JL, Kreider CM, Jia H, Castaneda G, Freytes IM, Cowper Ripley DC, et al. Telerehabilitation for rural veterans: A qualitative assessment of barriers and facilitators to implementation. Journal of Multidisciplinary Healthcare. 2020; 13:559-70. [DOI:10.2147/JMDH.S247267] [PMID]

[13] Aloyuni S, Alharbi R, Kashoo F, Alqahtani M, Alanazi A Alzhrani M, et al. Knowledge, attitude, and barriers to telerehabilitation-based physical therapy practice in Saudi Arabia. Healthcare. 2020; 8(4):460. [DOI:10.3390/healthcare8040460] [PMID]

[14] Annaswamy TM, Verduzco-Gutierrez M, Frieden L. Telemedicine barriers and challenges for persons with disabilities: Covid-19 and beyond. Disability and Health Journal. 2020; 13(4):100973. [DOI:10.1016/j.dhjo.2020.100973] [PMID]

[15] Leochico CFD, Espiritu AI, Ignacio SD, Mojica JAP. Challenges to the emergence of telerehabilitation in a developing country: A systematic review. Frontiers in Neurology. 2020; 11:1007. [DOI:10.3389/fneur.2020.01007] [PMID]

[16] Jafni TI, Bahari M, Ismail W, Hanafi MH. Exploring barriers that affect telerehabilitation readiness: A case study of Rehabilitation Centre in Malaysia. In: Saeed F, Gazem N, Mohammed F, Busalim A, editors. Recent trends in data science and soft computing. IRICT 2018. Advances in Intelligent
Systems and Computing. Cham: Springer; 2018. pp761-71. [DOI:10.1007/978-3-319-99007-1_70]

[17] Damhus CS, Emme C, Hansen H. Barriers and enablers of COPD telerehabilitation-a frontline staff perspective. International Journal of Chronic Obstructive Pulmonary Disease. 2018; 13:2473-82. [DOI:10.2147/COPD.S167501] [PMID]

[18] Shenoy MP, Shenoy PD. Identifying the challenges and cost-effectiveness of telerehabilitation: A narrative review. Journal of Clinical \& Diagnostic Research. 2018; 12(12):YE01-4. [DOI:10.7860/JCDR/2018/36811.12311]

[19] Calvaresi D, Schumacher M, Marinoni M, Hilfiker R, Dragoni AF, Buttazzo G. Agent-Based systems for telerehabilitation: Strengths, limitations and future challenges. In: Montagna S, Abreu P, Giroux S, Schumacher M, editors. Agents and multi-agent systems for health care. Cham: Springer; 2017. pp. 3-24. [DOI:10.1007/978-3-319-70887-4_1]

[20] Cason J, Cohn E. Telerehabilitation: Current challenges to deployment in the United States. Journal of the International Society for Telemedicine and eHealth. 2013; 1(2):73-7. https:/ / journals.ukzn.ac.za/index.php/JISfTeH/article/view/38

[21] Suso-Martí L, La Touche R, Herranz-Gómez A, Angulo-DíazParreño S, Paris-Alemany A, Cuenca-Martínez F. Effectiveness of telerehabilitation in physical therapist practice: An umbrella and mapping review with meta-meta-analysis. Physical Therapy. 2021; 101(5):pzab075. [DOI:10.1093/ptj/pzab075] [PMID]

[22] Rabanifar N, Abdi K. Rehabilitation services: Why should we use tele-rehabilitation in Iran? Necessity and application. Iranian Rehabilitation Journal. 2019; 17(4):293-6. [DOI:10.32598/irj.17.4.293] 
This Page Intentionally Left Blank 